\title{
Perancangan Sistem Absensi Online Menggunakan Android Guna Mempercepat Proses Kehadiran Karyawan Pada PT. Sintech Berkah Abadi
}

\author{
Al Husain ${ }^{1}$ \\ Abdul Haqy Aji Prastian'2 \\ Andre Ramadhan ${ }^{3}$ \\ Alamat : Jl. Jendral Sudirman No.40, Modernland, Tanggerang ${ }^{1,2,3}$ \\ E-mail : alhusain@raharja.info ${ }^{1}$, aji.prastian@raharja.info ${ }^{2}$, andre.ramadhan@ raharja.info ${ }^{3}$
}

\begin{abstract}
ABSTRAK
Sistem absensi saat ini perlu memerlukan pembaharuan sistem yang baru. Karena dengan melakukan hal ini akan berdampak sangat baik bagi perusahaan dilihat dari sisi efisien, efektif, dan cepat. Dalam hal ini perusahaan berlomba membuat sistem absensi yang dapat berjalan pada teknologi saat ini seperti smartphone android. Hal tersebut membutuhkan sebuah design rancangan sebelum sistem ini dibuat sehingga dapat mengetahui permasalahan dan solusi pada sistem yang akan dibuat. Design sistem absensi online digunakan untuk mempercepat absen hanya melalui smartphone android yang dimiliki oleh masing-masing karyawan. Hal ini membutuhkan jaringan lokal yang berjarak hanya didalam lingkungan perusahaan sehingga karyawan tidak dapat absen diluar perusahaan. Guna membuat sebuah laporan dengan metode sistem diatas, memerlukan metode pengumpulan data sistem yang berjalan, wawancara, observasi, analisa sistem yang diusulkan, dan metode prototipe dan testing sebagai pembentukan sistem usulan yang memadai sebagai alternative solusi terbaik dari permasalahan yang ada.
\end{abstract}

Kata Kunci : Sistem, Absensi, Design, Jaringan

\begin{abstract}
The current system requires absences need renewal of the new system. Because by doing this will have an impact is very good for the company as seen from the side of efficient, effective, and fast. In this case the company raced to make attendance system that can run on current technologies such as android smartphone. It requires adesign draft before this system was created so as to know the problems and solutions on the system to be created. Online attendance system design used to speed up the timesheet only through android smartphone which is owned by each employee.This requires a local network which is just in a corporate environment so that employees can not be absent outside of the company. To create a report with the methodabove, the system requires a method of data collection system that runs, interviews,observation, analysis of the proposed system, and the method of prototype and testing as the establishment of an adequate proposal system as alternative best solution of existing problems.
\end{abstract}

Key Word : System, Absence, Design, Network

105 |Al-Husain, Aji, Andre - Perancangan Sistem Absensi Online... 


\section{PENDAHULUAN}

Sistem absensi sangat penting dalam mengetahui kehadiran karyawan dalam suatu perusahaan. Perkembangan sistem absensi saat ini sudah berkembang dengan adanya teknologi pendukung seperti komputer dan gadget. Dari sistem absensi yang menggunakan kertas, program komputer, finger print, scan mata, dan sekarang sudah banyak yang beralih menggunakan gadget seperti android.

Dengan adanya smartphone android yang saat ini begitu banyak, memungkinkan beberapa perusahaan memperbaharui sistemnya menggunakan smartphone android. Karena lebih mudah pengoperasiannya dan dapat melakukan absensi dimana saja sehingga waktu yang dipergunakan tidak banyak terbuang.

Dalam hal penggunaan smartphone android sangatlah mudah, hampir lapisan masyarakat memiliki smartphone android. Dari yang ekonomi menengah sampai atas, dari anak kecil sampai orang dewasa memiliki smartphone android. Karena smartphone android memiliki banyak manfaat apabila dipakai untuk hal positif. Oleh karena itu, smartphone android diminati untuk mempermudah urusan seseorang.

Begitupun dengan sistem absensi, butuh pembaharuan yang sangat baik agar karyawan dapat absen dengan cepat dan tidak perlu antri untuk absen. Solusi yang terbaik adalah dengan menggunakan smartphone android. Sistem absensi dengan cara ini juga dapat memaksimalkan waktu perkerjaan dalam suatu perusahaan dibanding karyawan harus antri untuk tanda tangan pada form yang sudah disediakan atau antri didepan alat finger print. Hal ini sangat membuang waktu perkerjaan. Oleh sebab itu, penggunaan android sangatlah diperlukan dalam pembaharuan sistem absensi.

Apabila perusahaan beralih menggunakan smartphone android, perusahaan hanya perlu menyiapkan server untuk mengendalikan/mengatur data yang masuk dan pengaturan jam masuk dan pulang. Dan perlu juga jaringan WIFI lokal untuk menghubungkan smartphone android dengan server, jaringan ini juga di atur agar jangkauannya hanya wilayah perusahaan saja karena untuk menghindari karyawan curang yang absen dari luar perusahaan. Sistem absensi dengan cara ini sangatlah efektif dan harga yang dikeluarkan tergolong murah dan terjangkau.

\section{- Definisi Absensi}

Absensi berarti 'tidak hadir", namun bisa dikatakan pula absensi merupakan ketidakhadiran atau kehadiran suatu objek dalam hal ini adalah orang, dimana orang tersebut terlibat dalam suatu organisasi yang mengharuskan adanya pemberitahuan tentang keadaan atau kehadiran atau ketidakhadirannya dalam ruang lingkup organisasi tersebut."

Absensi sangat berpengaruh pada kinerja personal serta instansi dimana ia bekerja, yang dapat dijadikan pertimbangan terhadap tindak lanjut serta pembuatan keputusan bagi kelangsungan perkembangan instansi tersebut.

\section{- Definisi Android}

Menurut Teguh Arifianto (2011 : 1), android merupakan perangkat bergerak pada sistem operasi untuk telepon seluler yang berbasis linux.

Menurut Hermawan (2011 : 1), Android merupakan OS (Operating System) Mobile yang tumbuh ditengah OS lainnya yang berkembang dewasa ini. OS lainnya seperti Windows Mobile, i-Phone OS, Symbian, dan masih banyak lagi. Akan tetapi, OS yang ada ini berjalan dengan memprioritaskan aplikasi inti yang dibangun sendiri tanpa melihat potensi yang cukup besar dari 
aplikasi pihak ketiga. Oleh karena itu, adanya keterbatasan dari aplikasi pihak ketiga untuk mendapatkan data asli ponsel, berkomunikasi antar proses serta keterbatasan distribusi aplikasi pihak ketiga untuk platform mereka.

Dapat disimpulkan bahwa Android adalah sistem operasi atau OS yang dikembangkan oleh linux guna menjalankan perangkat smartphone sehingga smartphone dapat digunakan dengan tampilan dan performa yang baik.

\section{PERMASALAHAN}

Sistem absensi merupakan sistem yang diperlukan dalam setiap perusahaan. karena dengan sistem absensi pihak perusahaan dapat menilai kedisiplinan para karyawannya. Dalam sistem absensi juga terdapat banyak permalahan yang sering di pertanyakan. Adapun masalah yang dihadapi berdasarkan pengamatan / observasi dari sistem yang sedang berjalan saat ini adalah sebagai berikut:

1. Bagaimana sistem absensi saat ini dapat berjalan didalam perusahaan?

2. Apakah pengolahan data absensi yang dilakukan sudah sangat efektif?

3. Bagaimana keefektifan dari sistem absensi yang telah diperbaharui?

\section{LITERATURE REVIEW}

Sebagai salah satu upaya yang perlu dilakukan dalam penelitian untuk mengidentifikasi kesenjangan (identify gaps), menghindari pengulangan pembuatan (reinventing the wheel), mengidentifikasikan metode yang pernah dilakukan, serta mengetahui penerapan metode yang dilakukan orang lain dalam area penelitian yang mendekati bidang yang sama dengan penelitian ini, Maka berikut lima penelitian yang memiliki korelasi searah dengan penelitian yang akan dibahas:

1. Dalam jurnal penelitian yang dilakukan oleh Noval Aditya Muhammad, Febriliyan Samopa dan Radityo Prasetianto Wibowo dengan judul " Pembuatan Aplikasi Presensi Perkuliahan Berbasis Fingerprint" pada tahun 2013. Penelitian tersebut mengenai tentang sistem absensi berbasis fingerprint guna menunjang proses belajar mengajar, serta menanggulangi kecurangan presensi di kelas. Teknologi ini memang sedang marak dan sangat mendukung karena penerapannya tidak terlalu sulit lagipula terjangkau.Tetapi JSI belum memaksimalkan penerapan presensi fingerprint tersebut karena belum memiliki aplikasi yang mengelola presensi tersebut.

2. Dalam jurnal penelitian yang dilakukan oleh Wahyu Adam, M.Eng.Sc dan Lamhot Sagala dengan judul "Sistem Absensi Pegawai Menggunakan Teknologi RFID" pada tahun 2013. Penelitian ini bertujuan untuk merancang sebuah prototipe sistem absensi RFID yang terintegrasi dengan database untuk mendukung program peningkatan sikap displin karyawan sebagai langkah awal dari peningkatan kinerja kerja perusahaan secara keseluruhan.Prototipe RFID sistem absensi ini terdiri dari beberapa komponen utama, yaitu tag yang akan digunakan sebagai pengganti ID card dan reader yang digunakan untuk membaca informasi menyangkut kehadiran karyawan, integrasi database pada sistem ini akan memungkinkan dua untuk langsung disimpan secara otomatis ke dalam database.

3. Dalam jurnal penelitian yang dilakukan oleh Reymon Rotikan dengan judul "Sistem Informasi Absensi Berbasis Web Untuk Kegiatan Konferensi” pada tahun 2016. 
penelitian tentang sistem absensi berbasis Web dengan menggunakan Barcode yang dapat digunakan untuk setiap kegiatan konferensi. Pengembangan sistem absensi menggunakan metode Spiral yang memungkinkan pengembangan sistem secara sistematis dan iterative untuk setiap fiturnya. Hasil dari penelitian ini adalah sebuah sistem absensi yang dapat digunakan untuk mengambil absen di setiap sesi presentasi dalam sebuah kegiatan konferensi. Sistem juga dapat menampilkan laporan kehadiran untuk setiap sesi presentasi dan juga sesi presentasi yang paling diminati.

4. Dalam penelitian Tugas Akhir yang dilakukan oleh Eko Wijayanto dengan judul "Sistem Presensi Mahasiswa Dengan Fingerprint Berbasis Website" pada tahun 2017. Sistem presensi fingerprint bertujuan untuk menyingkat waktu pada saat proses pengambilan presensi. Selain itu, sistem akan mengurangi tingkat kecurangan mahasiswa terkait kehadiran mahasiswa. Dalam sistem ini, mahasiswa hanya akan diminta untuk mengunggah gambar sidik jarinya untuk menandai kehadiran mahasiswa. Pengembangan sistem ini menggunakan metode waterfall yang melibatkan integrasi dari berbagai teknologi open source berbasis website seperti MySQL, PHP dan Apache Web Server. Nantinya dalam sistem ini, dosen dapat mengetahui berbagai informasi terkait kehadiran mahasiswa. Hasil dari penelitian ini menunjukkan bahwa dengan menggunakan sistem ini dapat menyingkat waktu pada saat melakukan proses pengambilan presensi. Selain itu, mahasiswa juga tidak dapat lagi untuk melakukan kecurangan terkait kehadiran mahasiswa.

5. Dalam penelitian SKRIPSI yang dilakukan oleh Hartanto dengan judul "Perancangan Sistem Informasi Absensi Pegawai Dengan Barcode Scanner Card Pada Pt. Skyputra Pancasurya" pada tahun 2013. penelitian ini bertujuan untuk memperbaiki sistem absensi karyawan karena sistem yang masih manual menggunakan form kertas absensi yang akan di setorkan pada HRD untuk data. Oleh karena itu, peneliti menyarankan agar menggunakan barcode scanner dalam sistem absensi karena lebih mudah dalam pendataan absensi karyawan.

6. Dalam penelitian Jurnal yang dilakukan oleh Eko Budi Setiawan dan Bobi Kurniawan dengan judul "Perancangan Sistem Absensi Kehadiran Perkuliahan Dengan Menggunakan Radio Frequency Identification (RFId)" pada tahun 2015. Penelitian ini bertujuan untuk meminimalisir kesalahan yang ada dilingkungan perkuliahan yang berhubungan dengan masalah absensi sehingga dibuatlah sistem absensi dengan menggunakan RFId karena sangat efektif dan efisien.

7. Dalam penelitian Jurnal yang dilakukan oleh Taufik Ramadhan dan Victor G Utomo dengan judul "Rancang Bangun Aplikasi Mobile Untuk Notifikasi Jadwal Kuliah Berbasis Android" pada tahun 2014. Penelitian ini bertujuan untuk mempebaharui sistem terdahulu dengan aplikasi mobile yang berjalan pada android karena dalam hal penggunaan android lebih sangat efektif dan mudah.

8. Dalam penelitian Jurnal yang dilakukan oleh Rifa 'Atunnisa, Eri Satria dan Rinda Cahyana dengan judul "Pengembangan Aplikasi Zakat Berbasis Android Menggunakan Metode Prototype" pada tahun 2014. Penelitian ini bertujuan untuk mempermudah setiap orang dalam membayar zakat melalui aplikasi mobile. Karena android juga sudah banyak digunakan dalam lapisan masyarakat maka dalam pengimplementasiannya sangat mudah dalam hal apapun termasuk berzakat. 
9. Dalam penelitian Jurnal Internasional yang dilakukan oleh Charalampos Doukas, Thomas Pliakas, dan Ilias Maglogiannis dengan judul "Mobile Healthcare Infromation Management Utilizing Cloud Computing Dan Android OS" pada tahun 2014. Penelitian ini bertujuan untuk memberikan informasi medis dimanapun dan kapan saja. Karena terdapat pemantau pasien, lokasi medis, tanggap darurat, dan layanan informasi masyarakat. Tidak hanya dapat digunakan pada komputer, dari android pun dapat diakses.

10. Dalam International Journal, penelitian yang dilakukan oleh Jan Nealbert V. Calimag, Pamela Anne G. Miguel, Romel S. Conde, dan Luisa B. Aquino dengan judul "Ubiquitous Learning Environment Using Android Mobile Application" pada tahun 2014. Penelitian ini bertujuan untuk memperkenalkan penggunaan lingkungan e-learning berbasis Android untuk beradaptasi dengan gaya belajar dari peserta didik abad ke-21. Sistem ini memberikan pembelajaran e-learning modern dengan memanfa'atkan aplikasi mobile berbasis android.

\section{PEMECAHAN MASALAH}

Berdasarkan penelitian dan analisa kekurangan serta kebutuhan dalam proses sistem absensi pada perusahaan. sistem absensi yang berjalan saat ini belum begitu optimal dan efektif dalam proses absensi, sehingga memberikan alternative pemecahan masalah dengan cara :

1. Mempermudah karyawan dalam absensi dengan android.

Dalam penggunaannya android merupakan gadget yang sangat sering digunakan oleh setiap orang, oleh sebab itu dalam cara penggunaan juga setiap orang dapat menggunakan sangat mudah. Begitupun juga dengan adanya aplikasi absensi berbasis android, akan sangat mudah digunakan oleh karyawan.

2. Pengakses yang sangat cepat dalam hal absensi karena menggunakan android dan jaringan WLAN.

Dengan adanya akses melaui jaringan WLAN, maka aplikasi dapat digunakan melalui jaringan yang akan menghubungkan android dengan server. Karena untuk mentransfer data absensi yang telah dimasukan karyawan ke database server perlu adanya koneksi yang akan menghubungkan antara android sebagai client ke database server.

3. Dapat absensi dilingkungan perusahaan bebas dimana saja.

Karyawan dapat akses dilingkungan perusahaan secara bebas maksudnya karyawan dapat absen dimana pun dilingkungan perusahaan bukan diluar lingkungan perusahaan karena jangkauan jariangan WLAN hanya mencakup lingkungan perusahaan saja.

\section{PEMBAHASAN}

Sistem absensi online ini merupakan rancangan sistem yang dapat memudahkan dalam urusan kehadiran karyawan. Dengan adanya sistem ini diharapkan perusahaan dapat lebih produktif dalam menghasilkan sebuah produk, karena sistem yang dapat mempermudah dan mempercepat absensi maka waktu yang dibutuhkan dalam bekerja juga sangat efisien. Hal ini dapat mepercepat antrian dalam mengabsensi karyawan.

Sistem ini juga dapat menghasilkan laporan yang sangat akurat, karena data-data absensi sudah diolah oleh sistem dan direkap dengan rapih. 


\section{DESIGN SISTEM}

\section{Use Case Diagram}

Use Case Diagram merupakan sebuah teknik yang digunakan dalam pengembangan sebuah software atau sistem informasi untuk menangkap kebutuhan fungsional dari sistem yang bersangkutan.

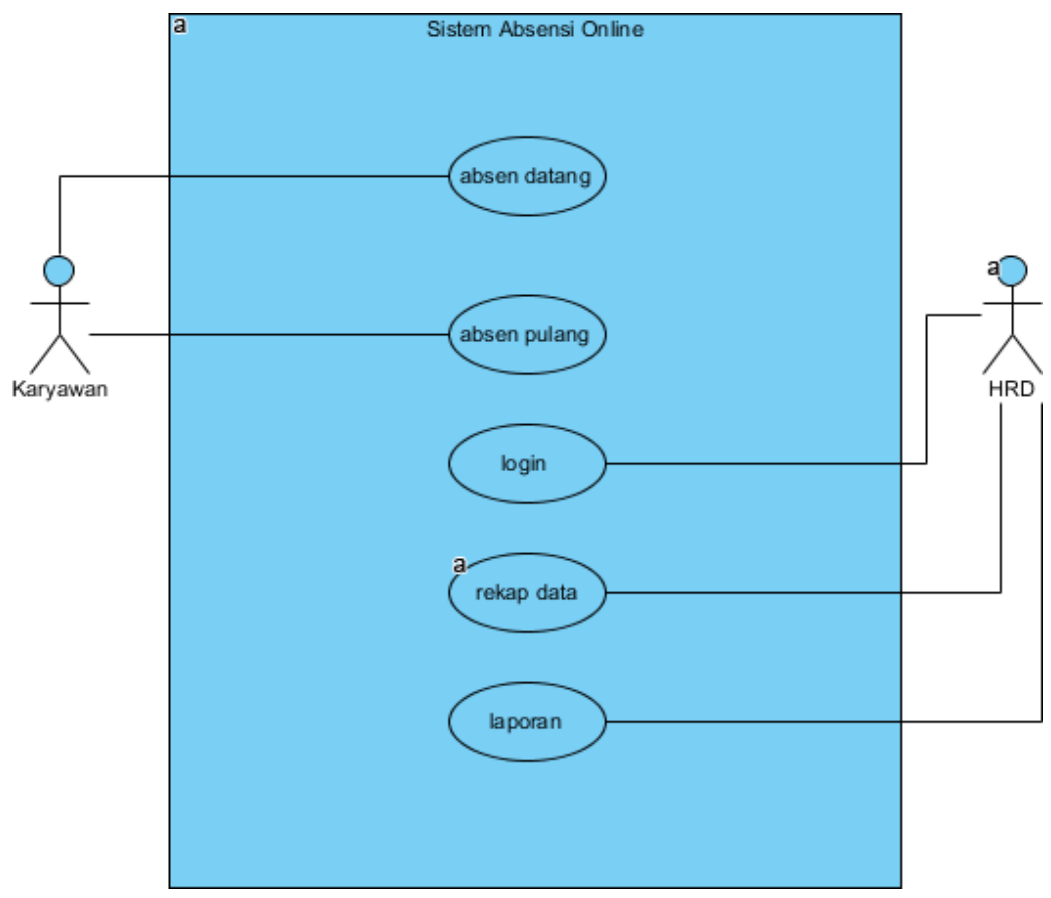

Gambar 1

Pada gambar 1 use case diagram diatas, terdapat 2 aktor yaitu : Karyawan, HRD, dan 5 use case yang dilakukan aktor-aktor tersebut.

\section{Activity Diagram}

Activity diagram adalah sesuatu yang menggambarkan berbagai alir aktivitas dalam sistem yang sedang dirancang

\section{Activity Diagram Karyawan}




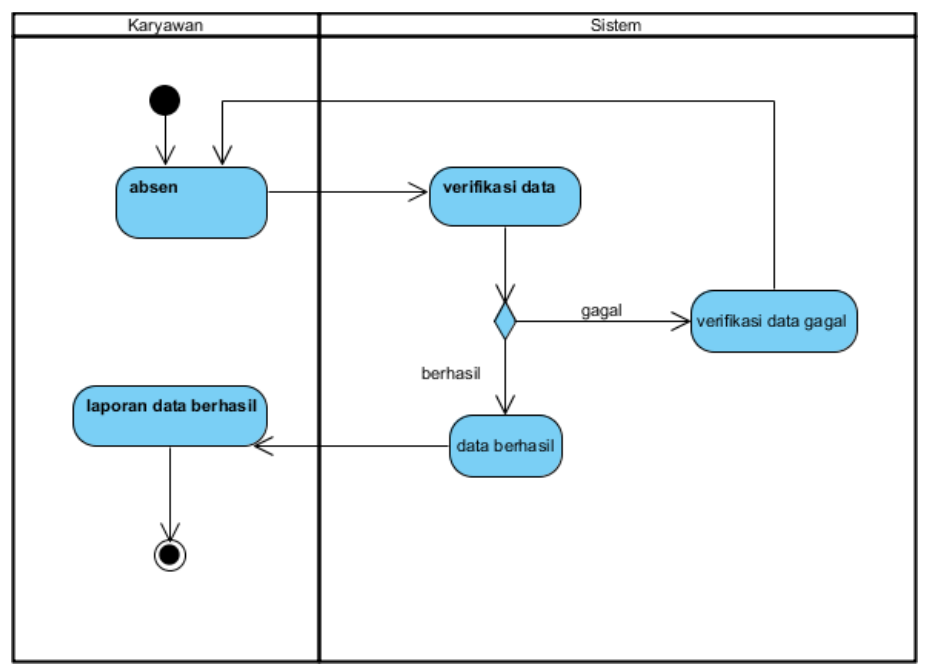

Gambar 2.1

Pada gambar 2.1 activity diagram, terdapat 2 partion yang meliputi Karyawan, dan Sistem dengan 3 activity yang menggambarkan proses absen karyawan, verifikasi data, laporan data berhasil dan 2 action yang menggambarkan proses berhasil atau gagal verifikasi yang dilakukan karyawan.

\section{Activity Diagram HRD}

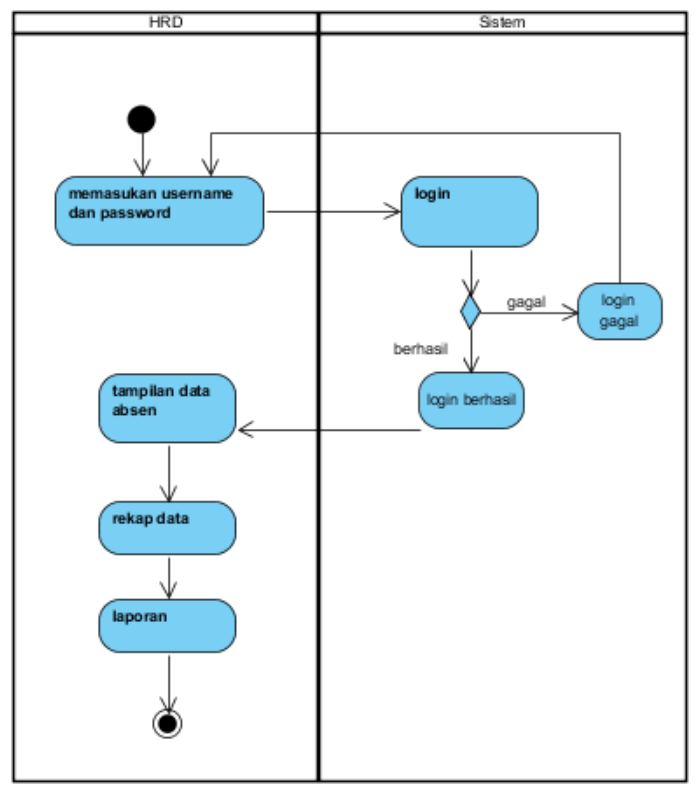

Gambar 2.2

Pada gambar 2.2 activity diagram, terdapat 2 partion yang meliputi HRD dan Sistem dengan 5 activity yang menggambarkan proses memasukan username dan password, login, tampilan data absen, rekap data, laporan dan 2 action yang menggambarkan proses berhasil atau gagal login yang dilakukan HRD.

Class Diagram

111 | Al-Husain, Aji, Andre - Perancangan Sistem Absensi Online... 
Class diagram adalah sebuah class yang menggambarkan struktur dan penjelasan class, paket, dan objek serta hubungan satu sama lain seperti containment, pewarisan, asosiasi, dan lain-lain.

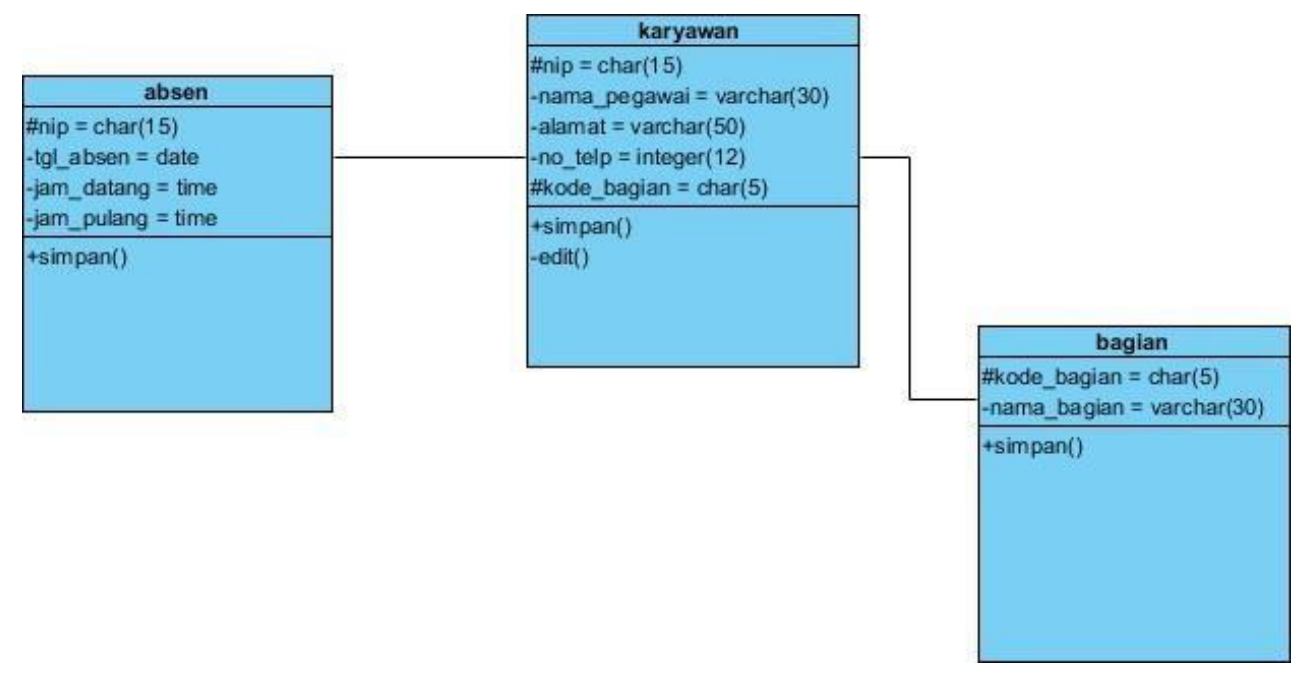

Gambar 3

Pada gambar 3 class diagram, terdapat 3 class yang meliputi karyawan, absen, dan bagian.

\section{DESIGN PROGRAM}

1. Tampilan utama mobile

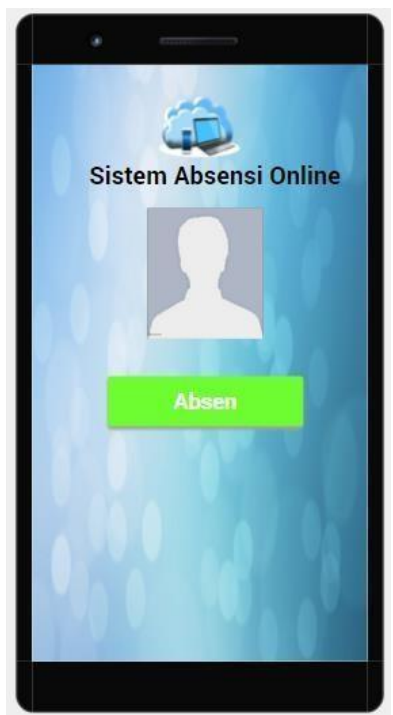

Gambar 4.1

112 |Al-Husain, Aji, Andre - Perancangan Sistem Absensi Online... 
Pada gambar 4.1 menunjukan halaman utama pada smartphone android, tampilan ini adalah tampilan untuk karyawan yang absen sesuai jadwal yang sudah ditentukan.

2. Tampilan absen berhasil

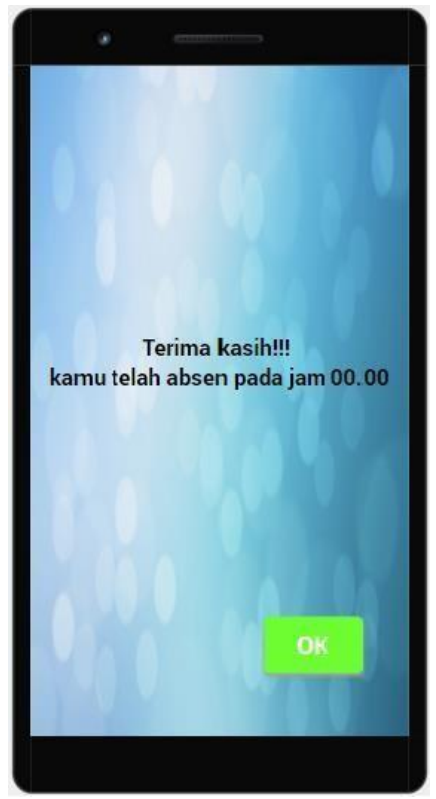

Gambar 4.2

Pada gambar 4.2 menunjukan tampilan pemberitahuan laporan untuk karyawan, sehingga karyawan dapat mengetahui absennya sudah masuk atau belum.

3. Tampilan login web

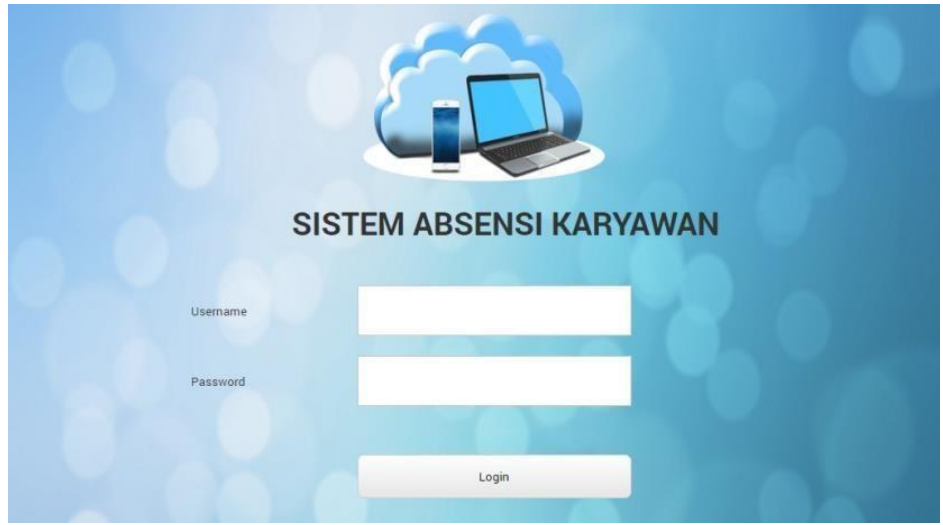

Gambar 4.3

Pada gambar 4.3 menunjukan tampilan login, tampilan ini digunakan untuk HRD sebagai pengamanan data karena hanya yang mempunyai hak akses saja yang dapat login dengan tampilan ini. 
4. Tampilan data absen

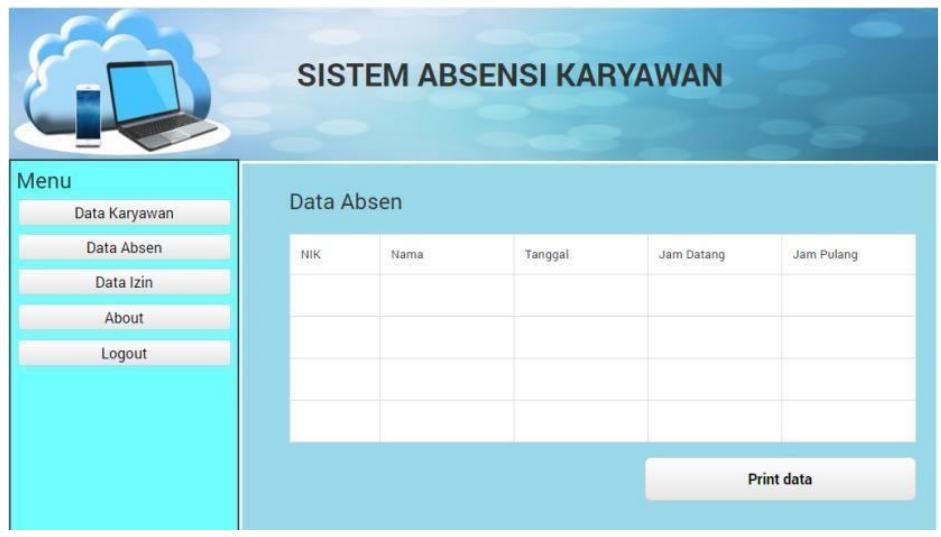

Gambar 4.4

Pada gambar 4.4 menunjukan tampilan data absen, dengan adanya tampilan seperti ini mempermudah bagi HRD untuk memonitoring semua kehadiran karyawan.

5. Tampilan data karyawan

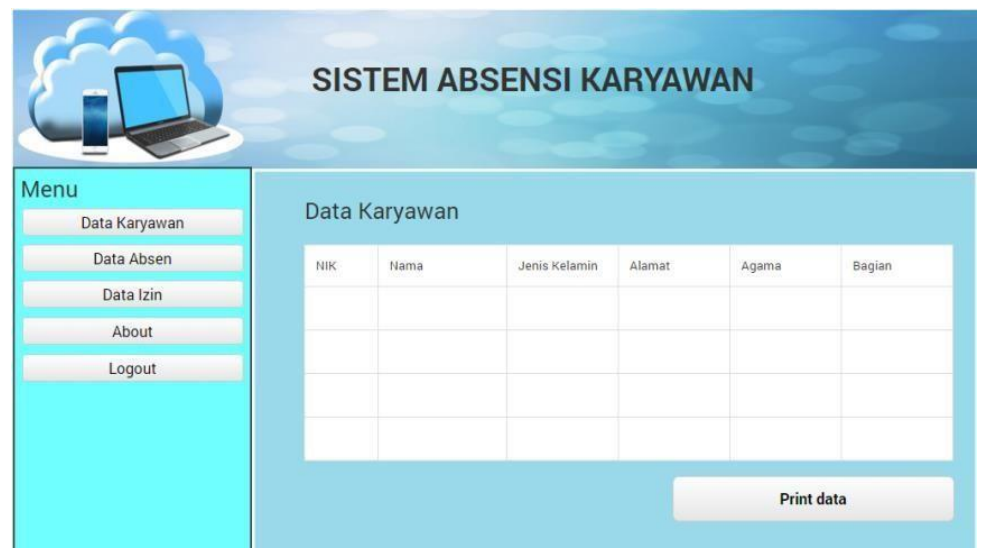

Gambar 4.5

Pada gambar 4.5 tampilan ini menunjukan sebagai data karyawan, karena data karyawan juga membutuhkan pengaman dan kerapihan data sehingga data yang disimpan dapat terjaga dengan sangat baik dan ketika diperlukan untuk mencari karyawan yang dituju akan sangat mudah untuk mencarinya.

\section{KELEBIHAN}

Kelebihan dari sistem absensi online adalah menggunakan android sehingga dapat mempermudah dalam absensi karyawan, akses yang sangat mudah dan cepat dengan menggunakan jaringan WLAN dan dapat diakses dimana pun didalam lingkungan perusahaan. 
dengan menerapakan sistem absensi online berbasis android diharapkan dapat mengoptimalkan pekerjaan karyawan, karena tidak perlu antri dan waktu pun dapat digunakan secara lebih efisien. Tidak memerlukan banyak alat karena smartphone android sudah menjadi kebutuhan setiap orang, oleh sebab itu mungkin setiap karyawan mempunyai smartphone android untuk digunakan untuk absensi.

\section{KEKURANGAN}

Kekurangan dari sistem absensi online adalah apabila salah seorang karyawan mengalami kerusakan pada smartphone android-nya maka harus absen dengan memberitahukan pada pihak perusahaan dengan menggunakan surat yang mungkin sudah disediakan oleh perusahaan. dan juga apabila kerusakan pada WLAN sehingga karyawan tidak bisa absen. Oleh sebab itu, diperlukan juga perawatan/maintenance terhadap performa dari jaringan WLAN dan juga database server.

\section{KESIMPULAN}

Sistem absensi yang dikembangkan menggunakan teknologi yang ada saat ini seperti android memungkinkan perusahaan mendapat keuntungan yang sangat banyak, karena akan mempermudah dan mempercepat karyawan dalam hal absensi. Hal ini juga berpengaruh pada laporan yang akan dibuat oleh HRD, karena data yang ada di sistem tertata rapih sehingga untuk membuat laporan akan sangat mudah. Dalam hal merancang sistem absensi online berbasis android diperlukan metode yang baik dan penelitian yang berlanjut agar kedepannya sistem ini sangat bermanfa'at bagi perusahaan.

Dengan adanya sistem absensi online ini, karyawan dapat mengoptimalkan pekerjaan dengan sangat baik. Karena sistem absensi ini diakses sangat mudah dan waktu pun dapat digunakan secara efisien

\section{DAFTAR PUSTAKA}

[1] Husain, Al, Jaka Prima Maulana dan Yuli Widiastuti. 2016. Perancangan Sistem Aplikasi Request Maintenance Teknik Di Perguruan Tinggi Raharja. Tangerang: Perguruan Tinggi Raharja.

[2] Muha mmad, Noval Aditya, Febriliyan Samopa dan Radityo Prasetianto Wibowo. 2013. Pembuatan Aplikasi Presensi Perkuliahan Berbasis Fingerprint. Surabaya: Institut Teknologi Sepuluh Nopember.

m, Wahyu, M.Eng.Sc, dan Lamhot Sagala. 2013. Sistem Absensi Pegawai Menggunakan Teknologi RFID. Bandung: STMIK LPKIA.

an, Reymon. 2016. Sistem Informasi Absensi Berbasis Web Untuk Kegiatan Konferensi. Pontianak: STMIK Pontianak.

yanto, Eko. 2017. Sistem Presensi Mahasiswa Dengan Fingerprint Berbasis Website. Surakarta: Universitas Muhammadiyah Surakarta. 
[6] Hartanto. 2013. Perancangan Sistem Informasi Absensi Pegawai Dengan Barcode Scanner Card Pada Pt. Skyputra Pancasurya. Tangerang: Perguruan Tinggi Raharja.

[7] Setiawan, Eko Budi dan Bobi Kurniawan. 2015. Perancangan Sistem Absensi Kehadiran Perkuliahan Dengan Menggunakan Radio Frequency Identification (RFId). Bandung: Universitas Komputer Indonesia.

[8] Ramadhan, Taufik dan Victor G Utomo. 2014. Rancang Bangun Aplikasi Mobile Untuk Notifikasi Jadwal Kuliah Berbasis Android. Semarang: STMIK Provisi Semarang.

[9] 'Atunnisa, Rifa, Eri Satria dan Rinda Cahyana. 2014. Pengembangan Aplikasi Zakat Berbasis Android Menggunakan Metode Prototype. Garut: Sekolah Tinggi Teknologi Garut.

[10] Doukas, Charalampos, Thomas Pliakas, dan Ilias Maglogiannis. 2010. Mobile Healthcare Infromation Management Utilizing Cloud Computing Dan Android OS. Argentina : IEEE Publisher.

[11] Calimag, Jan Nealbert V., Pamela Anne G. Miguel, Romel S. Conde, dan Luisa B. Aquino. 2015. Ubiquitous Learning Environment Using Android Mobile Application. Philippines: University of Saint Louis.

dari : https://medium.com/@arifwicaksanaa/pengertian-use-

casea7e576e1b6bf\#.nqk6w9yke. (07 Maret 2017).

Merta. 2016. "Pengertian Activity Diagram". Diambil dari : http://otodidak13.blogspot.co.id/2016/04/pengertian-activity-diagram.html (07 Maret 2017)

[14] Liana, Nur. 2014. "Pengertian Class Diagram". Diambil dari : https://nurliana23.wordpress.com/2014/12/14/class-diagram-pengertian-penjelasan-danrelasi/ (07 Maret 2017). 